\title{
Fixed point problems of nonexpansive mappings for nononvex set in Hilbert spaces
}

\author{
Xianbing Wu \\ Department of Mathematics Yangtze Normal University, Chongqing, China \\ E-mail: flwxbing@163.com
}

Received 19 September 2019; accepted 1 October 2019

DOI https://doi.org/10.21595/vp.2019.21034

Check for updates

Copyright $(2019$ Xianbing Wu. This is an open access article distributed under the Creative Commons Attribution License, which permits unrestricted use, distribution, and reproduction in any medium, provided the original work is properly cited.

\begin{abstract}
In this paper, we introduce a new concept of $\mathrm{W}$-nonexpansive mappings and obtain fixed point theorems for nonexpansive mappings for non-convex set. Our results resolve fixed pointed problem that nonexpansive mappings be not on closed convex set, and it extends fixed point theorems for nonexpansive mappings.
\end{abstract}

Keywords: W-nonexpansive mapping, Hilbert space, fixed point theorem, non-convex set.

\section{Introduction and preliminaries}

Fixed point theory is widely applied in engineering. Browder (1965) [1], Kirk (1965) [2] obtained fixed points theorem for nonexpansive mapping. Non-expansion fixed point theory has made great progress, large number of results are obtained by authors (e.g. See [3-11]). let's come up with some definitions.

Definition 1.1 Let $X$ be a nonempty set, the function $W: X \times X \rightarrow[0, \infty)$ is called triangular if for all $x, y \in X$, if $W(x, y) \geq 1, W(y, z) \geq 1$ or $W(y, x) \geq 1, W(y, z) \geq 1$, then $W(x, z) \geq 1$.

Definition 1.2 Let $(X, d)$ be a metric space and $T: X \rightarrow X$ be a given mapping, if there exists a function $W: X \times X \rightarrow[0, \infty)$ such that $W(x, y) d(T x, T y) \leq d(x, y), \forall x, y \in X$, then we say that $T$ is a $W$-nonexpansive mapping.

Clearly, any nonexpansive mapping is a $W$-nonexpansive mapping with $W(x, y)=1$ for all $x, y \in X$.

Definition 1.3 Let $T: X \rightarrow X$ be a mapping and $W: X \times X \rightarrow[0, \infty)$ be a function. We say that $T$ is a $W$-admissible if $W(x, y) \geq 1 \Rightarrow W(T x, T y) \geq 1, \forall x, y \in X$.

Definition 1.4 [4] Let $H$ be a Hilbert space, $T: H \rightarrow H$ is called demicompact if whenever $\left\{x_{n}\right\} \subset H$ is bounded and $\left\{T x_{n}-T x_{n}\right\}$ strongly convergent, then there exists a subsequence $\left\{x_{n k}\right\}$ of $\left\{x_{n}\right\}$ which is strongly convergent.

Next our main results are presented.

\section{Main results}

Theorem 2.1 Let $E$ be a bounded closed convex subset of a Hilbert space $H, W: E \times E \rightarrow$ $[0, \infty)$ is triangular function, $T: E \rightarrow E$ is a $W$-nonexpansive mapping and it is $W$-admissible. If the following conditions are satisfied:

(w1) there exists $x_{0} \in E$ such that $W\left(x_{0}, T x_{0}\right) \geq 1$;

(w2) there exists a sequence $\left\{s_{j}\right\} \subseteq[0,1)$ with $\lim _{n \rightarrow \infty} s_{j}=1$ such that for all $x, y \in E$, if $W(x, y) \geq 1$, then $W\left(x,\left(1-s_{j}\right) x+s_{j} y\right) \geq 1, \forall s_{j} \in\left\{s_{j}\right\}$

(w3) if $\left\{x_{n}\right\} \subseteq E$ is satisfied $W\left(x_{0}, x_{n}\right) \geq 1$, moreover $x_{n} \rightarrow x^{*}$ or $x_{n} \rightarrow x^{*} \in E$, then $W\left(x_{n}, x *\right) \geq 1$.

Then $T$ has a fixed point.

Proof. Let $x_{0} \in X$ such that $\alpha\left(x_{0}, T x_{0}\right) \geq 1$. Take $x_{n+1 j}=\left(1-s_{j}\right) x_{0}+s_{j} T x_{n j}$ for all $j$, $n \in N$, there $x_{0}=x_{0 j}$. Now we fix $j$, for each $j \in N$, from (w2), we may obtain $W\left(x_{0 j}, x_{1 j}\right) \geq 1$.

Also, for $T$ is $W$-admissible, then $W\left(T x_{0 j}, T x_{1 j}\right) \geq 1$ is obtained. According to $W$ is a 
triangular function and (w1), then $W\left(x_{0 j}, T x_{1 j}\right) \geq 1$.

Once again use (w2), then $W\left(x_{0 j}, x_{2 j}\right) \geq 1$ is also obtained. Continuously, we easily obtain:

$W\left(x_{0 j}, x_{n j}\right) \geq 1, \quad \forall n \in N$

Based on that $W$ is triangular, we may get:

$W\left(x_{n j}, x_{m j}\right) \geq 1, \forall n, m \in N, n<m$.

So from Eq. (2) and for $T$ is $W$-nonexpansive, we have:

$$
\begin{aligned}
& \left\|x_{n j}-x_{m j}\right\|=s_{j}\left\|T x_{n-1 j}-T x_{m-1 j}\right\| \leq s_{j} W\left(x_{n-1 j}, x_{m-1 j}\right)\left\|T x_{n-1 j}-T x_{m-1 j}\right\| \\
& \quad \leq s_{j}\left\|x_{n-1 j}-x_{m-1 j}\right\| \ldots \leq s_{j}^{n}\left\|x_{0 j}-x_{m-n j}\right\| .
\end{aligned}
$$

Let $n \rightarrow \infty$, for $E$ is bounded we may get $\left\|x_{n j}-x_{m j}\right\| \rightarrow 0$, hence $\left\{x_{n j}\right\}$ is Cauchy sequence, it means there exists $x_{j}^{*} \in E$ such that $\left\{x_{n j}\right\}$ convergent to $x_{j}^{*}$, that is:

$\lim _{n \rightarrow \infty}\left\|x_{n j}-x_{j}^{*}\right\|=0$

Also, from Eq. (1) and (w3), we have:

$W\left(x_{n j}, x_{j}^{*}\right) \geq 1$

Once again by Eq. (1), for $W$ is triangular, so we have:

$W\left(x_{0 j}, x_{j}^{*}\right) \geq 1$.

Since $E$ is bounded, closed and convex in Hilbert $H$, then it is weakly compact. Hence there exists a $x^{*} \in E$ such that:

$x_{j}^{*} \rightarrow x^{*}, \quad(j \rightarrow \infty)$.

From Eqs. $(6,7)$, applying (w3) we have:

$W\left(x_{j}^{*}, x^{*}\right) \geq 1$.

Next, we show that $x_{j}^{*}=\left(1-s_{j}\right) x_{0 j}+s_{j} T x_{j}^{*}$. have:

Indeed, according to $x_{n j}=\left(1-s_{j}\right) x_{0}+s_{j} T x_{n-1 j}, T$ is $W$-nonexpiansive and Eq. (5), we

$$
\begin{aligned}
& \left\|x_{j}^{*}-\left(\left(1-s_{j}\right) x_{0 j}+s_{j} T x_{j}^{*}\right)\right\|=\left\|x_{j}^{*}-x_{n j}+x_{n j}-\left(\left(1-s_{j}\right) x_{0 j}+s_{j} T x_{j}^{*}\right)\right\| \\
& \quad=\left\|x_{n j}-x_{j}^{*}\right\|+s_{j}\left\|T x_{n-1 j}-T x_{j}^{*}\right\| \leq\left\|x_{n j}-x_{j}^{*}\right\|+s_{j} W\left(x_{n j}, x_{j}^{*}\right)\left\|T x_{n-1 j}-T x_{j}^{*}\right\| \\
& \quad \leq\left\|x_{n j}-x_{j}^{*}\right\|+s_{j}\left\|x_{n-1 j}-x_{j}^{*}\right\| .
\end{aligned}
$$

Let $n \rightarrow \infty$ in Eq. (9), utilize Eq. (4) we obtain $\left\|x_{j}^{*}-\left[\left(1-s_{j}\right) x_{0 j}+s_{j} T x_{j}^{*}\right]\right\| \rightarrow 0$, it implies that $x_{j}^{*}=\left(1-s_{j}\right) x_{0 j}+s_{j} T x_{j}^{*}$.

Finally, we show that $x^{*}$ is a fixed point of $T$. If $y$ is any arbitrary point in $H$, we have:

$$
\left\|x_{j}^{*}-y\right\|^{2}=\left\|\left(x_{j}^{*}-x^{*}\right)+\left(x^{*}-y\right)\right\|^{2}=\left\|x_{j}^{*}-x^{*}\right\|^{2}+\left\|x^{*}-y\right\|^{2}+2\left\langle x_{j}^{*}-x^{*}, x^{*}-y\right\rangle .
$$


Since $x_{j}^{*} \rightarrow x^{*}$, then $2\left\langle x_{j}^{*}-x^{*}, x^{*}-y\right\rangle \rightarrow 0,(j \rightarrow \infty)$.

So, based on the above inequality and Eq. (10), we get:

$\lim _{j \rightarrow \infty}\left(\left\|x_{j}^{*}-y\right\|^{2}-\left\|x_{j}^{*}-x^{*}\right\|^{2}\right)=\left\|x^{*}-y\right\|^{2}$.

Setting $y=T x^{*}$ in Eq. (11), we have:

$\lim _{j \rightarrow \infty}\left(\left\|x_{j}^{*}-T x^{*}\right\|^{2}-\left\|x_{j}^{*}-x^{*}\right\|^{2}\right)=\left\|x^{*}-T x^{*}\right\|^{2}$.

Moreover, since $x_{j}^{*}=\left(1-s_{j}\right) x_{0 j}+s_{j} T x_{j}^{*}$, then:

$\left\|T x_{j}^{*}-x_{j}^{*}\right\|=\left\|T x_{j}^{*}-\left(1-s_{j}\right) x_{0 j}-s_{j} T x_{j}^{*}\right\|=\left(1-s_{j}\right)\left\|T x_{j}^{*}-x_{0 j}\right\|$.

So, in Eq. (13) as $j \rightarrow \infty$, for $\lim _{j \rightarrow \infty} S_{j}=1$ we have:

$\left\|T x_{j}^{*}-x_{j}^{*}\right\| \rightarrow 0$.

On the other hand, from Eq. (8) and since $T$ is $W$-nonexpansive mapping, we have:

$\left\|T x_{j}^{*}-T x^{*}\right\| \leq W\left(x_{j}^{*}, x^{*}\right)\left\|T x_{j}^{*}-T x^{*}\right\| \leq\left\|x_{j}^{*}-x^{*}\right\|$.

Thus:

$\left\|x_{j}^{*}-T x^{*}\right\| \leq\left\|x_{j}^{*}-T x_{j}^{*}\right\|+\left\|T x_{j}^{*}-T x^{*}\right\| \leq\left\|x_{j}^{*}-T x_{j}^{*}\right\|+\left\|x_{j}^{*}-x^{*}\right\|$,

in turn:

$\left\|x_{j}^{*}-T x^{*}\right\|-\left\|x_{j}^{*}-x^{*}\right\| \leq\left\|x_{j}^{*}-T x_{j}^{*}\right\|$.

Hence by Eq. (14), we have:

$\lim _{j \rightarrow \infty}\left(\left\|x_{j}^{*}-T x^{*}\right\|-\left\|x_{j}^{*}-x^{*}\right\|\right) \leq \lim _{j \rightarrow \infty}\left\|x_{j}^{*}-T x_{j}^{*}\right\|=0$.

And, due to $E$ is bounded, we have also:

$$
\begin{aligned}
& \lim _{j \rightarrow \infty}\left(\left\|x_{j}^{*}-T x_{*}\right\|^{2}-\left\|x_{j}^{*}-x^{*}\right\|^{2}\right) \\
& \quad=\lim _{j \rightarrow \infty}\left(\left\|x_{j}^{*}-T x_{*}\right\|-\left\|x_{j}^{*}-x^{*}\right\|\right)\left(\left\|x_{j}^{*}-T x_{*}\right\|+\left\|x_{j}^{*}-x^{*}\right\|\right) \leq 0 .
\end{aligned}
$$

So, by Eq. (12), we get $\left\|x^{*}-T x_{*}\right\|^{2}=0$, that is, $x^{*}$ is fixed point of $T$.

Now, we provide a method for computation of that fixed point $x^{*}$.

Theorem 2.2 Suppose all conditions of the Theorem 2.1 are satisfied. Then the Krasnoselskij iteration $\left\{x_{n}\right\}_{0}^{\infty}$ given by:

$x_{n+1}=(1-s) x_{n}+s T x_{n}, \quad s \in\left\{s_{j}\right\}_{j \in N}, \quad n=0,1,2, \ldots$,

converges to a fixed point of $T$.

Proof. Take the same $x_{0} \in E$ as Theorem 2.1, and such that $W\left(x_{0}, T x_{0}\right) \geq 1$. From (w2) we get: 
$W\left(x_{0},(1-s) x_{0}+s T x_{0}\right)=W\left(x_{0}, x_{1}\right) \geq 1$.

For $W$ is triangular, so:

$W\left(T x_{0}, x_{1}\right) \geq 1$.

Since $T$ is a $W$-admissible, from Eq. (20) we have:

$W\left(T x_{0}, T x_{1}\right) \geq 1$

Once again for $W$ is triangular, by Eqs. (21) and (22) we have $W\left(x_{1}, T x_{1}\right) \geq 1$.

Also, from (w2) we have $W\left(x_{1},(1-s) x_{1}+s T x_{1}\right)=W\left(x_{1}, x_{2}\right) \geq 1$.

Continuously, we can obtain:

$W\left(x_{n}, x_{m}\right) \geq 1, \quad \forall n, m \in N, \quad n<m$.

Hence:

$W\left(x_{0}, x_{n}\right) \geq 1$

Also form Theorem 2.1, we know that $x_{*}$ is fixed point of $T$, and Based on all conditions of Theorem 2.1 are satisfied in Theorem 2.2, similarly we have:

$W\left(x_{0}, x_{j}^{*}\right) \geq 1$,

$W\left(x_{j}^{*}, x^{*}\right) \geq 1$.

From Eqs. (25) and (26), for $W$ is triangular, then:

$W\left(x_{0}, x^{*}\right) \geq 1$.

Also, by Eqs. (24) and (27), use $W$ is triangular, we get:

$W\left(x_{n}, x^{*}\right) \geq 1$.

Based on Eq. (28), since $T$ is $W$-nonexpansive mapping, then we have:

$\left\|T x_{n}-T x^{*}\right\| \leq W\left(x_{n}, x^{*}\right)\left\|T x_{n}-T x^{*}\right\| \leq\left\|x_{n}-x^{*}\right\|$.

So:

$$
\begin{aligned}
& \left\|x_{n+1}-x^{*}\right\|=\left\|(1-s)\left(x_{n}-x^{*}\right)+s\left(T x_{n}-T x^{*}\right)\right\| \\
& \quad \leq(1-s)\left\|\left(x_{n}-x^{*}\right)\right\|+s\left\|T x_{n}-T x^{*}\right\| \\
& \quad \leq(1-s)\left\|\left(x_{n}-x^{*}\right)\right\|+s\left\|x_{n}-x^{*}\right\|=\left\|\left(x_{n}-x^{*}\right)\right\| .
\end{aligned}
$$

Continuously, we have $\left\|x_{n+1}-x^{*}\right\| \leq\left\|x_{0}-x^{*}\right\|$, which implies that $\left\{\left\|x_{n+1}-x^{*}\right\|\right\}$ is monotone decrease bounded sequence. So $\lim _{n \rightarrow \infty}\left\|x_{n+1}-x^{*}\right\|$ exists.

Next, we prove that $\left\|x_{n}-T x_{n}\right\| \rightarrow 0:$

$$
\begin{aligned}
& \left\|x_{n+1}-x^{*}\right\|^{2}=\left\|(1-s)\left(x_{n}-x^{*}\right)-s\left(T x_{n}-T x^{*}\right)\right\|^{2} \\
& \quad=(1-s)^{2}\left\|x_{n}-x^{*}\right\|^{2}+s^{2}\left\|T x_{n}-T x^{*}\right\|^{2}+2(1-s) s\left\langle x_{n}-x^{*}, T x_{n}-T x^{*}\right\rangle \\
& \quad \leq(1-s)^{2}\left\|x_{n}-x^{*}\right\|^{2}+s^{2}\left\|x_{n}-x^{*}\right\|^{2}+2(1-s) s\left\langle x_{n}-x^{*}, T x_{n}-T x^{*}\right\rangle \\
& \quad=\left((1-s)^{2}+s^{2}\right)\left\|x_{n}-x^{*}\right\|^{2}+2(1-s) s\left\langle x_{n}-x^{*}, T x_{n}-T x^{*}\right\rangle .
\end{aligned}
$$


Also, on the other hand for any constant $\lambda$ :

$$
\begin{aligned}
& \lambda^{2}\left\|x_{n}-T x_{n}\right\|^{2}=\left\|\left(x_{n}-x^{*}\right)-\left(T x_{n}-T x^{*}\right)\right\|^{2} \\
& \quad=\lambda^{2}\left\|x_{n}-x^{*}\right\|^{2}+\lambda^{2}\left\|T x_{n}-T x^{*}\right\|^{2}-2 \lambda^{2}\left\langle x_{n}-x^{*}, T x_{n}-T x^{*}\right\rangle \\
& \quad \leq \lambda^{2}\left\|x_{n}-x^{*}\right\|^{2}+\lambda^{2}\left\|x_{n}-x^{*}\right\|^{2}-2 \lambda^{2}\left\langle x_{n}-x^{*}, T x_{n}-T x^{*}\right\rangle \\
& \quad=2 \lambda^{2}\left\|x_{n}-x^{*}\right\|^{2}-2 \lambda^{2}\left\langle x_{n}-x^{*}, T x_{n}-T x^{*}\right\rangle
\end{aligned}
$$

Adding Eq. (31) to Eq. (32) and let $\lambda^{2} \leq(1-s) s$, we may obtain:

$$
\begin{aligned}
& \left\|x_{n+1}-x^{*}\right\|^{2}+\lambda^{2}\left\|x_{n}-T x_{n}\right\|^{2} \leq\left((1-s)^{2}+s^{2}+2 \lambda^{2}\right)\left\|x_{n}-x^{*}\right\|^{2} \\
& \quad+\left(2(1-s) s-2 \lambda^{2}\right)\left\langle x_{n}-x^{*}, T x_{n}-T x^{*}\right\rangle \\
& \quad \leq\left((1-s)^{2}+s^{2}+2 \lambda^{2}+2(1-s) s-2 \lambda^{2}\right)\left\|x_{n}-x^{*}\right\|^{2}=\left\|x_{n}-x^{*}\right\|^{2} .
\end{aligned}
$$

It implies $\lambda^{2}\left\|x_{n}-T x_{n}\right\|^{2} \leq\left\|x_{n}-x^{*}\right\|^{2}-\left\|x_{n+1}-x^{*}\right\|^{2}$.

Since $\lim _{n \rightarrow \infty}\left\|x_{n+1}-x^{*}\right\|$ exists, in the above inequality let $n \rightarrow \infty$, it results $\lambda^{2}\left\|x_{n}-T x_{n}\right\|^{2} \rightarrow 0$.

It means $\left\|x_{n}-T x_{n}\right\| \rightarrow 0$.

For $T$ is demicompact, it results that there exists a strongly convergent subsequence $\left\{x_{n_{i}}\right\} \subseteq\left\{x_{n}\right\}$ such that $x_{n_{i}} \rightarrow x^{*} \in F(T)$, that is, $\left\|x_{n_{i}} \rightarrow x^{*}\right\| \rightarrow 0$. Also $\left\{\left\|x_{n} \rightarrow x^{*}\right\|\right\}$ is convergent, it implies that $\left\|x_{n} \rightarrow x^{*}\right\| \rightarrow 0$. Hence that $\left\{x_{n}\right\}$ is convergent to $x^{*} \in F(T)$.

\section{Acknowledgements}

This work was supported by the Educational Science Foundation of Chongqing.

\section{References}

[1] Browder F. E. Nonexpansive nonlinear operators in a Banach space. Proceedings of the National Academy of Sciences of the United States of America, Vol. 54, 1965, p. 1041-1044.

[2] Kirk W. A. A fixed point theorem for mappings which do not increase distance. American Mathematical Monthly, Vol. 72, 165, p. 1004-1006.

[3] Browder F. E. Construction of fixed points of nonlinear mappings in Hilbert space. Journal of Mathematical Analysis and Applications, Vol. 20, Issue 2, 1967, p. 197-228.

[4] Amini-Harandi A., Fakhar M. Approximate fixed points of $\alpha$-nonexpamsive mappings. Journal of Mathematical Analysis and Applications, Vol. 462, Issue 2, 2018, p. 1168-1173.

[5] Shimizu T., Takahashi W. Strong convergence to common fixed points of families of nonexpansive mapping. Journal of Mathematical Analysis and Applications, Vol. 222, Issue 1, 1997, p. 71-83.

[6] Tang J. F., Chang Shih-Sen General split feasibility problems for two families of nonexpansive mappings in Hilbert spaces. Acta Mathematica Scientia, Vol. 36, Issue 2, 2016, p. 602-603.

[7] O'hara J. G., Pillay P., Xu H. K. Iterative approaches to finding nearest common fixed points of nonexpansive mappings in Hilbert spaces. Nonlinear Analysis: Theory, Methods and Applications, Vol. 54, Issue 8, 2003, p. 1417-1426.

[8] Lee B. S., Chang Shih-Sen Fixed points for nonexpansive fuzzy mappings in locally convex space. Fuzzy Sets and Systems, Vol. 76, Issue 2, 1995, p. 247-251.

[9] Hierro A. F. R. L. D., Shahzad N. New fixed point theorem under R-contractions. Fixed Point Theory and Applications, Vol. 2015, 2015, p. 176.

[10] Samet B., Vetro C., Vetro P. Fixed point theorems for $\alpha$ - $\psi$-contractive type mappings. Nonlinear Analysis, Vol. 75, 2012, p. 2154-2165.

[11] Karapinar E., Samet B. Generalized $\alpha-\psi$ contractive type mappings and related fixed point theorems with applications. Abstract and Applied Analysis, Vol. 2012, 2012, p. 793486. 